\title{
Recommended "Best Practices" for Chirp Acquisition and Processing
}

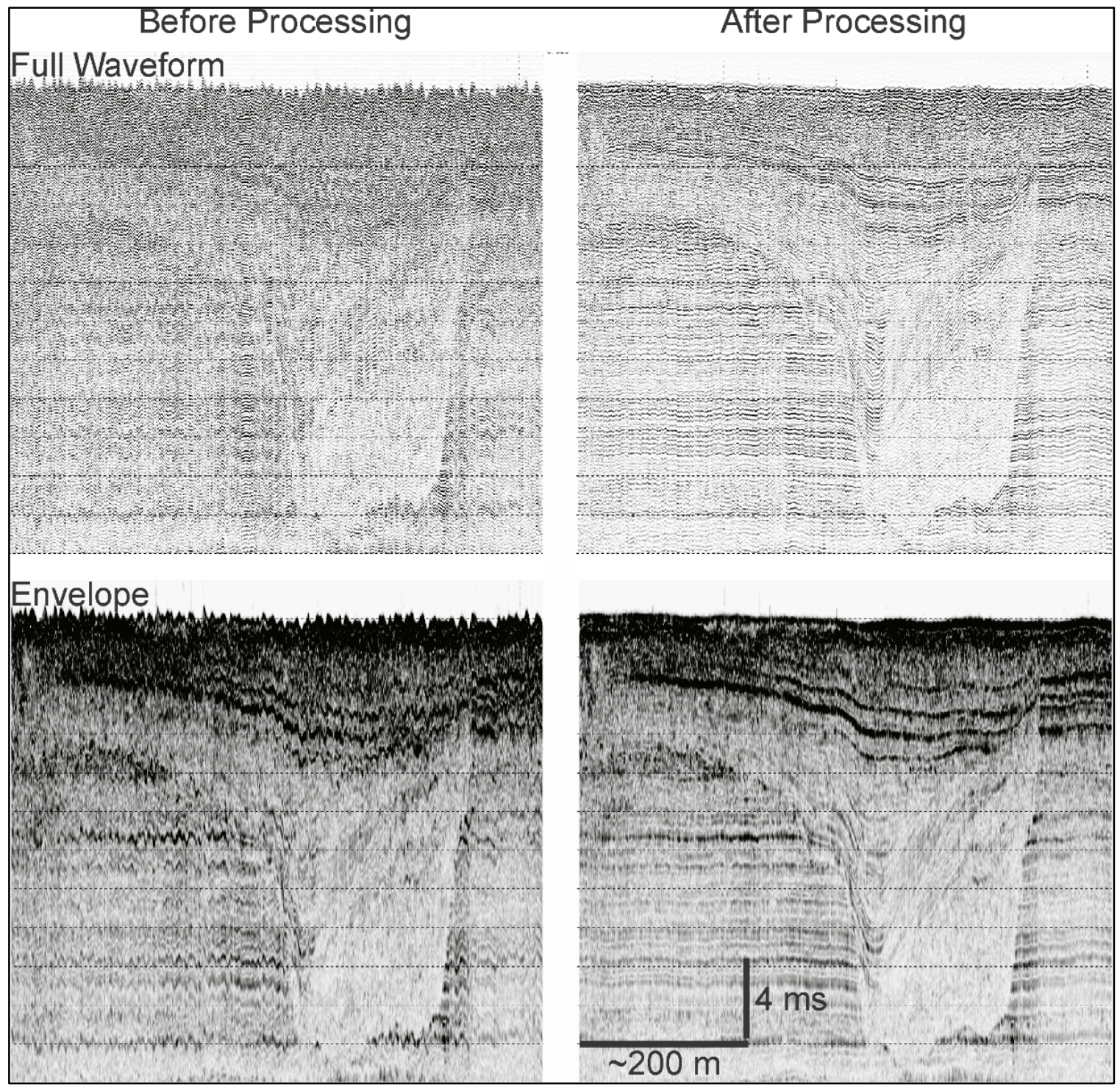





\section{Recommended "Best Practices" for Chirp Acquisition and Processing}

Authors

Steffen Saustrup

John A. Goff

Sean P.S. Gulick

Prepared under Agreement M16AC00020

by

University of Texas Institute for Geophysics

J.J. Pickle Research Campus, Bldg. 196

10100 Burnet Rd. (R2200)

Austin, TX 78758-4445

Published by 



\section{DISCLAIMER}

The Cooperative Agreement and funding were provided by the U.S. Department of the Interior, Bureau of Ocean Energy Management (BOEM) under Agreement Number M16AC00020. This report has been technically reviewed by BOEM, and it has been approved for publication. The views and conclusions contained in this document are those of the authors and should not be interpreted as representing the opinions or policies of the U.S. Government, nor does mention of trade names or commercial products constitute endorsement or recommendation for use.

\section{REPORT AVAILABILITY}

To download a PDF file of this report, go to the U.S. Department of the Interior, Bureau of Ocean Energy Management, Marine Minerals website at https://www.boem.gov/Marine-MineralResource-Evaluation/.

\section{CITATION}

Saustrup, S., J.A. Goff, and S.P.S. Gulick. 2018. Recommended "best practices" for chirp acquisition and processing. U.S. Dept. of the Interior, Bureau of Ocean Energy Management, Gulf of Mexico OCS Region, New Orleans, LA. OCS Report BOEM 2019-039. ix + 16 pp.

\section{ABOUT THE COVER}

Examples of pre- and post-processed chirp acoustic reflection data, both for full-waveform and envelope records.

\section{ACKNOWLEDGEMENTS}

The authors acknowledge helpful review and input from Mike Miner, John Swartz, Jim Flocks, Jeff Waldner, Lora Turner, Beau Suthard, and Hsing-Zen Mark Lee. This is the University of Texas Institute for Geophysics Contribution \#3289. 



\section{CONTENTS}

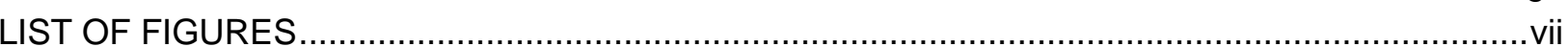

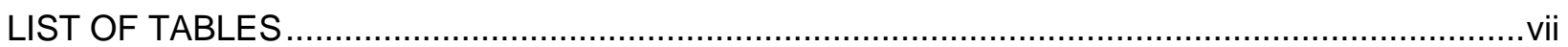

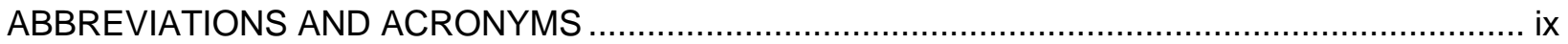

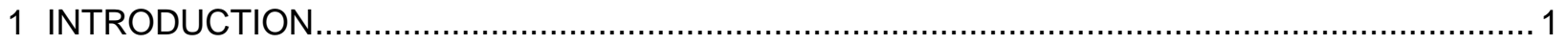

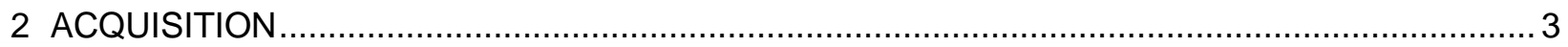

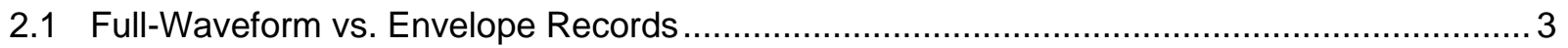

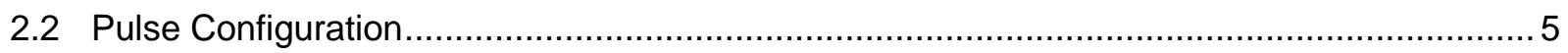

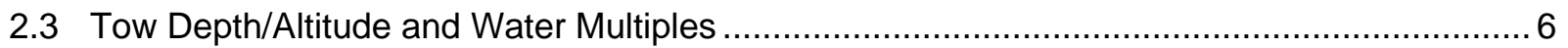

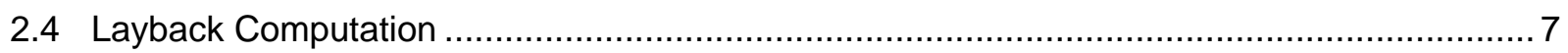

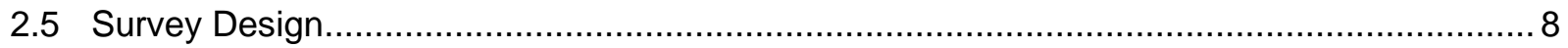

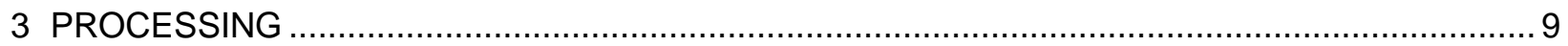

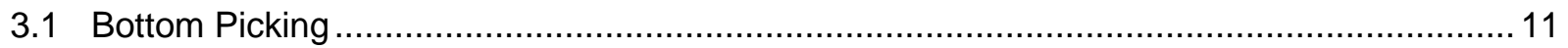

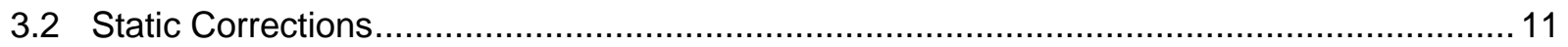

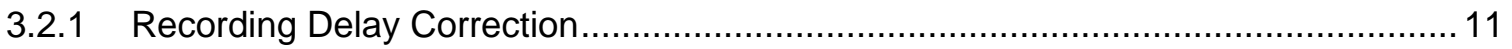

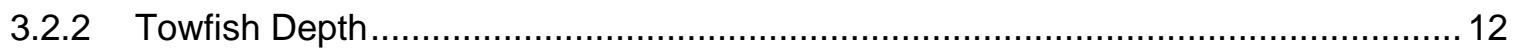

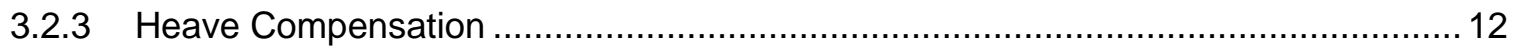

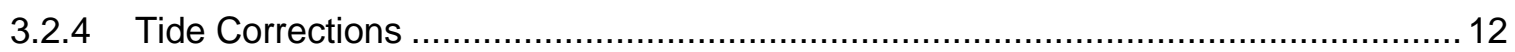

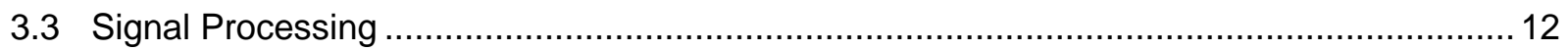

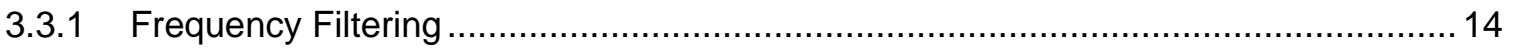

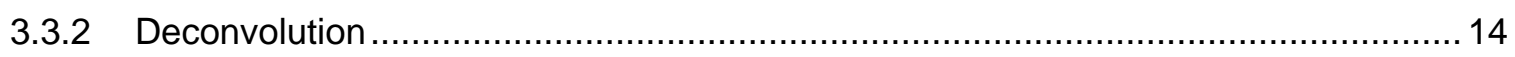

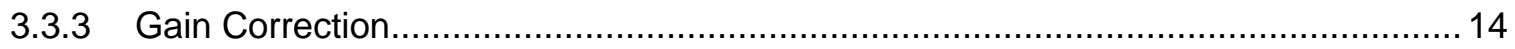

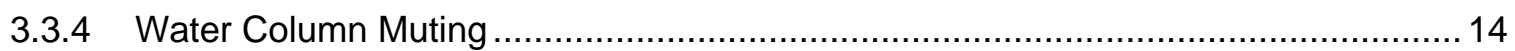

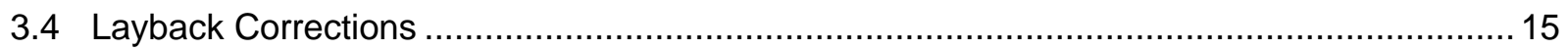

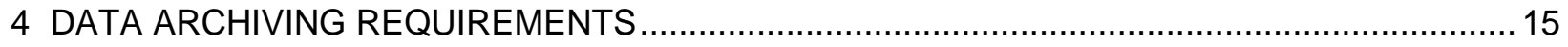

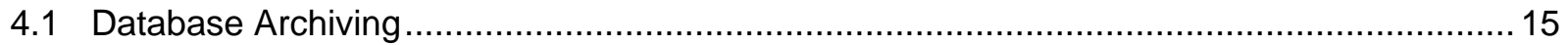

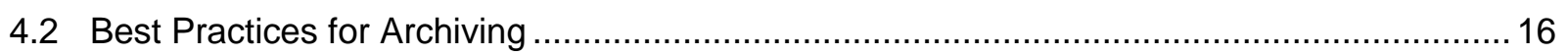

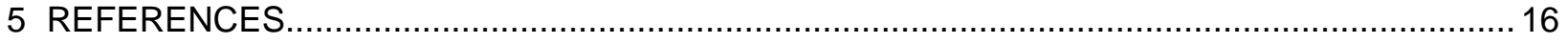





\section{LIST OF FIGURES}

Page

Figure 1. Waveform vs. Envelope Sketch Illustration of the Rlationship Between

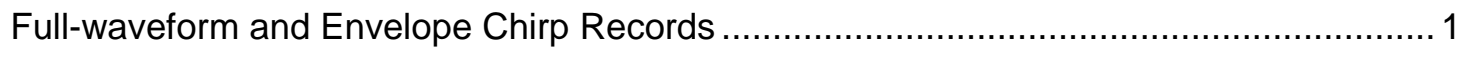

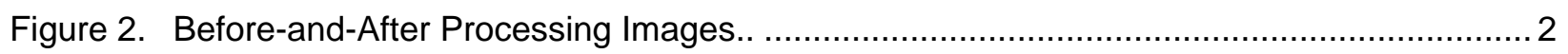

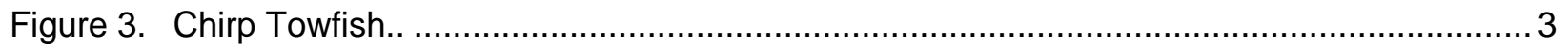

Figure 4. Comparison of Detailed Envelope and Waveform Chirp Records. ................................ 4

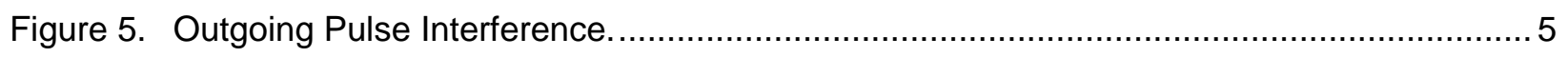

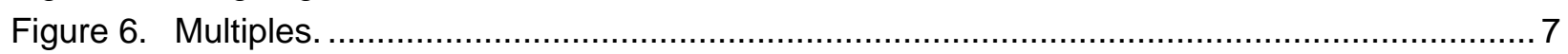

Figure 7. Examples of Before-and-After Processing of Full-waveform and Envelope Chirp

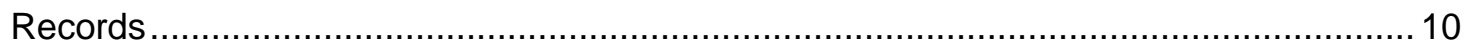

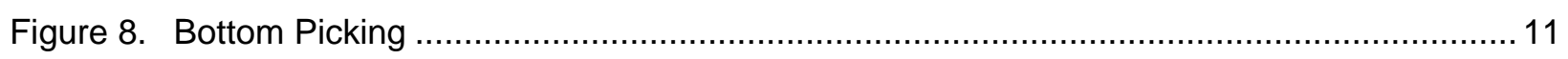

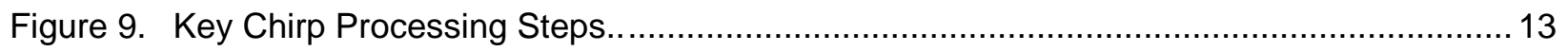

\section{LIST OF TABLES}

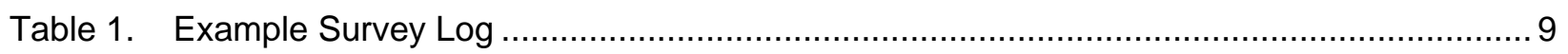





\section{ABBREVIATIONS AND ACRONYMS}

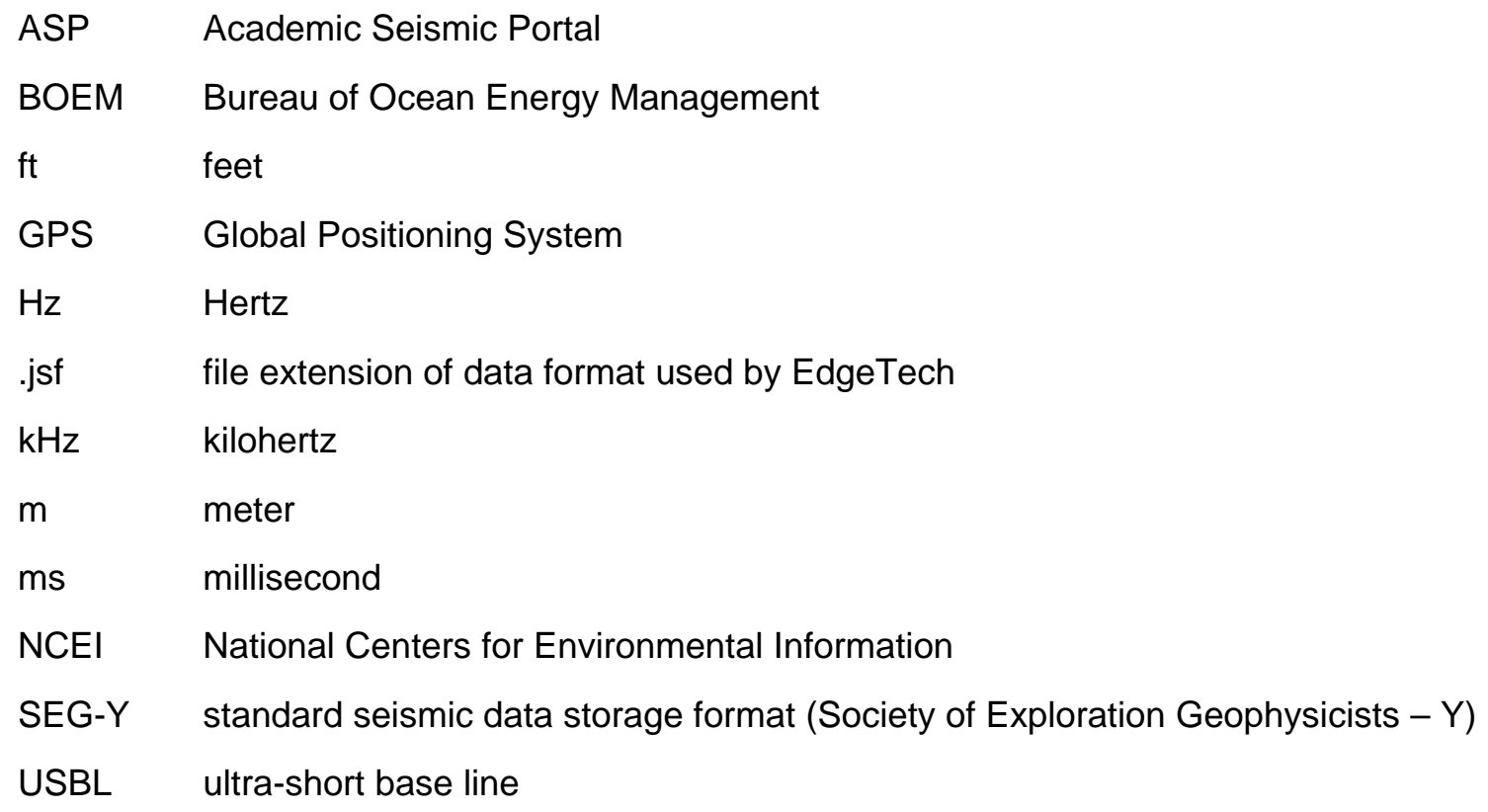





\section{INTRODUCTION}

Chirp acoustic reflection systems, sometimes called subbottom profilers, are an invaluable tool for ultra-high resolution ( decimeter scale) imaging of sediments beneath a seabed or lake bed. Chirp is a signal processing technique developed by the radar community for improving the resolution of echo returns (Klauder et al., 1960). The technique was later adapted by the sonar community (Schock et al., 1989). The chirp signal is a swept-frequency pulse, typically ranging between 5 and 30 milliseconds ( $\mathrm{ms}$ ) in length, over frequencies that range from 0.5 kilohertz $(\mathrm{kHz})$ to $24 \mathrm{kHz}$, depending on the transducers. The essential feature of chirp signal processing is to match-filter (i.e., apply a deconvolution) the return signal with the known outgoing pulse function, which will, theoretically, collapse a composite reflection from the long and complicated outgoing sonar pulse into a near-impulse response and, thus, single reflections from each sub-surface layer. Chirp data are acquired in time, where the Z-axis is the travel time from chirp to a reflector (seafloor or deeper layer that has an acoustic response) and back to the chirp (two-way time). Some chirp acquisition systems automatically display the data with a Z-axis of depth based on an assumed sound velocity in water (e.g., 1,500 meters [m] [4,921 feet; ft] per second); however, the recorded data are always in two-way time. The horizontal axis is pings or traces that are converted to distance along the survey track based on global positioning system (GPS) navigation for each sonar ping.

Full-waveform records (Figure 1), with positive and negative values, are the first product of the chirp after match-filtering (convolving) the return signal with the modeled outgoing wavelet (match filtering is analogous to deconvolution intended to collapse a very complex signal to a narrow response function). The envelope record (Figure 1), which is far more commonly displayed by users, is a fit of a positive-definite envelope over the top of the sinusoidal full-waveform records. It is very useful for improving contrast, especially when looking at data plotted at larger scale. The full-waveform records, however, tend to be much better at expressing fine detail and can be processed to extract more quantitative information regarding the subbottom. So, though they are derived from the same source, the two types of records are complimentary in many ways and both very useful.

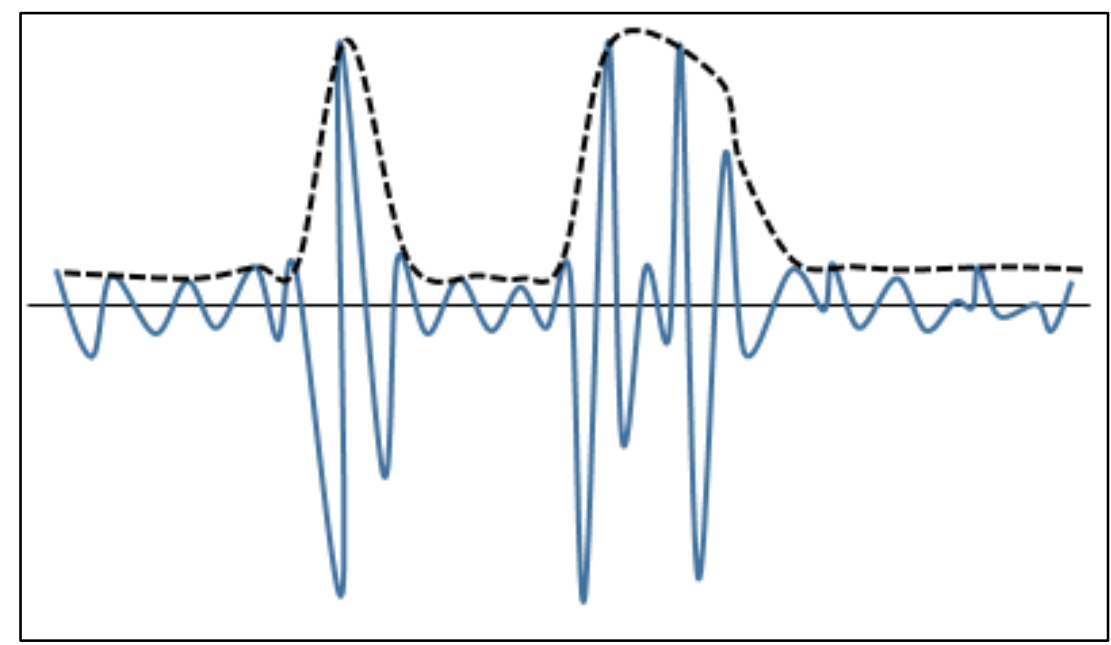

Figure 1. Waveform vs. Envelope Sketch Illustration of the Relationship Between Full-waveform (blue) and Envelope (dashed black) Chirp Records. 
Match-filtered, envelope-processed output of chirp systems often generates images that are fairly interpretable without any additional processing. Therefore, many chirp data collectors will treat this standard output as a final product. This turn-key approach often proves to be a lost-opportunity. Many chirp images can, in fact, be significantly improved with some conventional full-waveform seismic processing techniques. Figure 2 demonstrates some typical imaging improvements that are possible. In this example, the raw image is degraded by heave artifacts due to vessel motion and associated variations in the amplitude of the return signal. Processing the data with a heave filter relative to the seafloor arrival, and amplitude normalization, dramatically improve the image quality as well as its interpretability. Furthermore, imaging of the full-waveform record, in addition to the envelope record (refer to Chapter 2.1), often provides far greater stratigraphic detail.

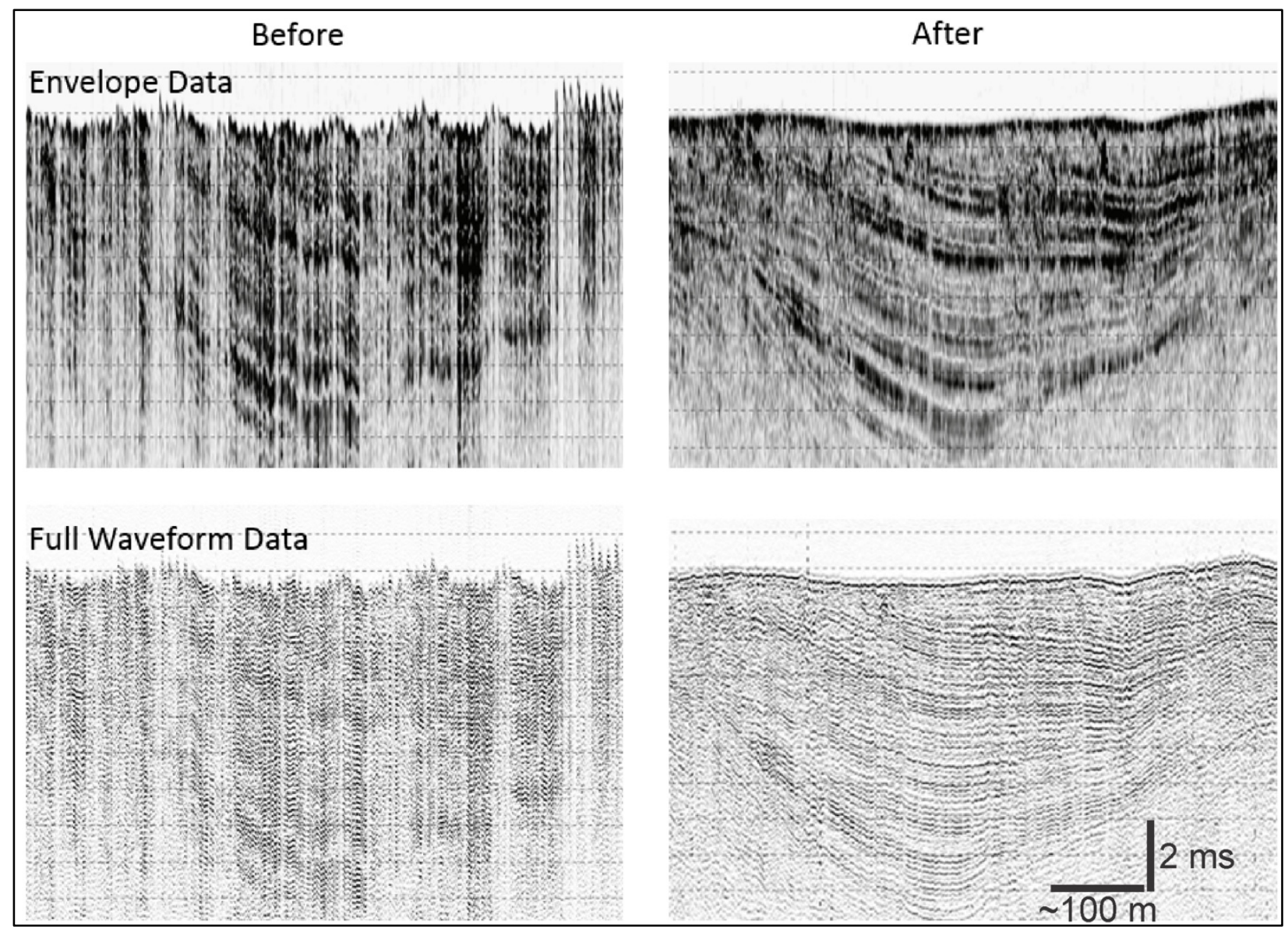

Figure 2. Before-and-After Processing Images. (Chirp processing scheme applied to both envelope and full-waveform [real] data. These data were collected offshore on the Rio Grande Delta with a 20-ms 0.7-12 kHz pulse.)

The University of Texas Institute for Geophysics has been working with marine seismic reflection data since its founding in 1972. For the past two decades we have applied such expertise to the acquisition, processing, and interpretation of chirp data, primarily in continental shelf and coastal settings. We have recently entered into a cooperative agreement with the U.S. Department of the Interior, Bureau of Ocean and Energy Management (BOEM), two goals of which are to (1) generate a white paper to document "best practices" in chirp acquisition and processing based on our experiences 
and (2) update our in-house chirp processing schemes to be better automated, user-friendly, and transportable to other platforms. This document serves the first of those two goals. All of the illustrations of our processing methods in this document are produced by the updated processing scheme pursuant to the second goal. Our new processing scheme is intended to use typical algorithms contained within widely available seismic processing packages; we have developed it using Paradigm's Echos software and will make our Echos scripts freely available via Internet download. In this document, we use our Echos results to illustrate our processing steps. However, future efforts will explore portability to other seismic processing packages (e.g., SonarWiz).

Our primary experience in acquisition and processing primarily involves the EdgeTech 3200 subbottom profiling system (EdgeTech, N.D.) operated with a SB-0512i or SB-216S towfish (Figure 3). This chirp system is widely used in government, academia, and industry. However, the basic practices and principals we describe should be applicable to any chirp system. For example, we applied many of these techniques on data acquired by Knudsen 3260 hull-mounted systems with similar results (e.g., Gulick et al., 2017).
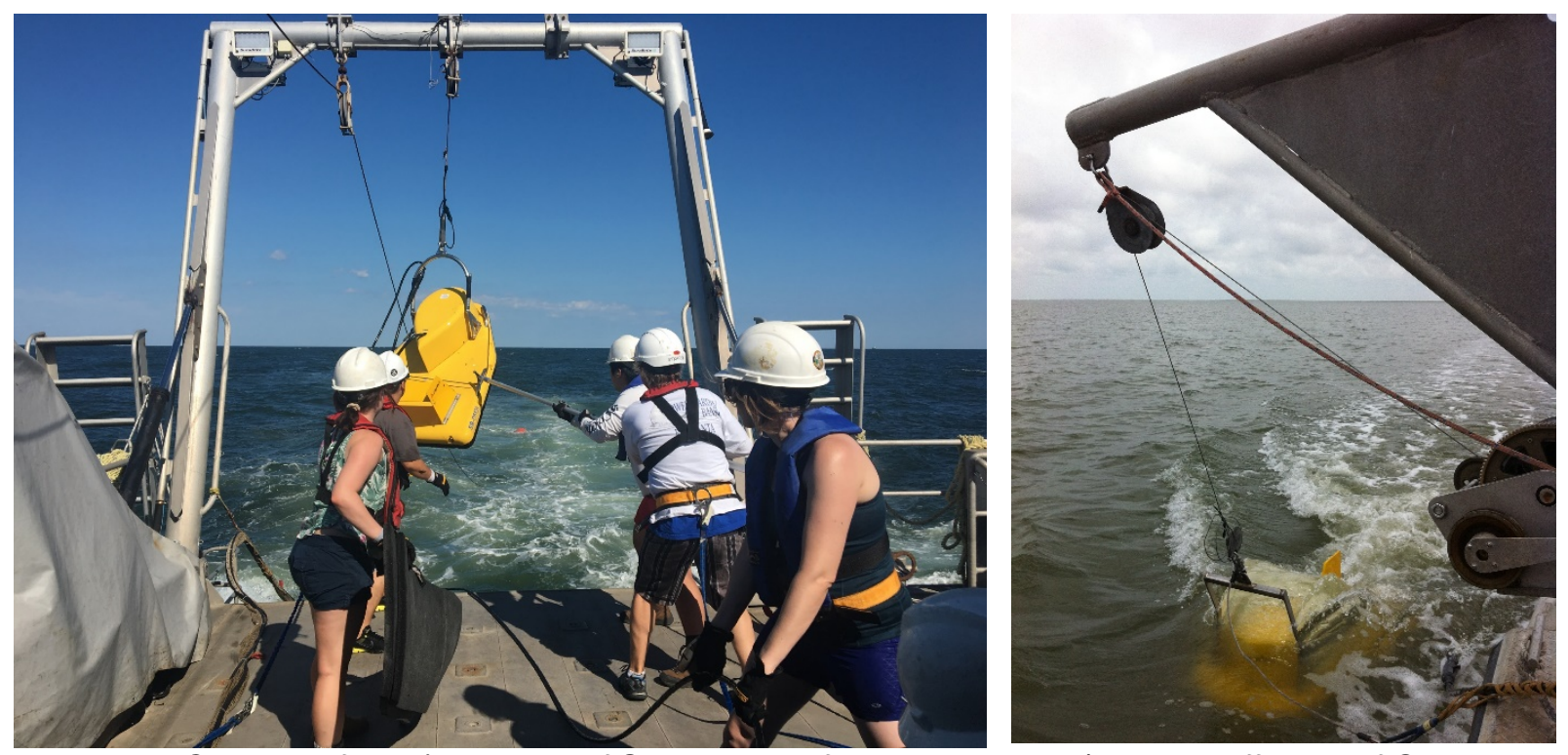

Figure 3. Chirp Towfish. (Recovery of SB-0512i towfish aboard the R/V Manta offshore of Galveston, Texas [left], and shallow-tow of SB-216S towfish with side-davit aboard the R/V Itasca in East Bay, Texas [right])

\section{ACQUISITION}

\subsection{FULL-WAVEFORM VS. ENVELOPE RECORDS}

The chirp's match-filter generates, as its primary output, a full-waveform record of sinusoidal aspect (i.e., both positive and negative values). However, it is common practice with chirp systems to transform full-waveform records into envelope records, which provide a higher contrast spectrum but contain positive values only. Many chirp operators use only the envelope record as the basis for interpretation. Figure 2 displays both types of records. Although the two records are derived from the same data source, the images are complimentary in important ways. We find, for example, that the 
envelope record is more interpretable at larger scale and is more robustly interpretable where heave and amplitude artifacts are not processed (compare, for example, the unprocessed envelope versus full-waveform images in Figure 2). The full-waveform record, in contrast, does not display well at larger scales, tending to appear noisy because the positive and negative values are intermingled at such scales. However, when the full-waveform image is enlarged, the record often contains significantly greater detail, particularly after data processing. These differences can also be expressed in terms of frequency content; full-waveform data have content out to $\sim 8,000$ hertz $(\mathrm{Hz})$, whereas the envelope show content is only out to about $300 \mathrm{~Hz}$. Thus, the envelope record is a filtered version of the full-waveform record.

The greater resolving capabilities of the full-waveform record are demonstrated in Figure 4. These data, collected over the New England Mud Patch, south of Cape Cod, image a mud layer at the seafloor deposited atop a sand facies (Twichell et al., 1981; Goff et al., 2016). Many of the details that are observable in the full-waveform record, such as dipping horizons within the sand bodies and horizontal layering within the overlying mud, are poorly imaged, if at all, in the envelope record. Our recommended best practice is to acquire, process, and interpret both types of data in order to have greater confidence in the stratigraphic interpretation at all scales.

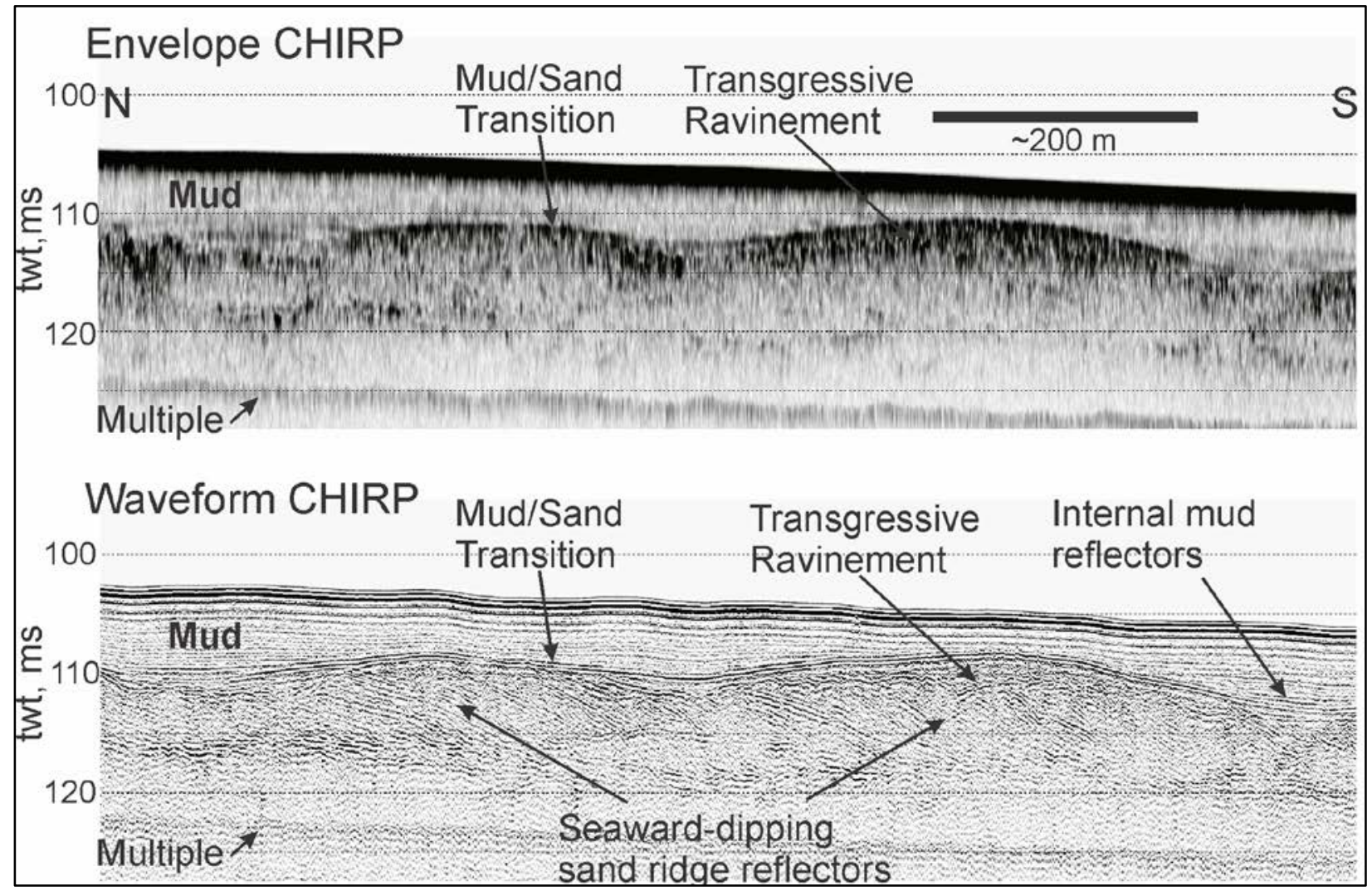

Figure 4. Comparison of Detailed Envelope and Waveform Chirp Records. (Data were collected over the New England Mud Patch [Goff et al., 2016], south of Cape Cod, Massachusetts, with a SB-0512i towfish using a 30-ms 0.5-7.2 kHz pulse. Both profiles have been processed with steps described in Chapter 3.2. Water-bottom multiple is observed on both record types [refer to Chapter 2.3]. Z-axis is two-way time.) 


\subsection{Pulse Configuration}

Chirp systems typically offer the operator a range of pulse choices with varying frequency ranges (which are dependent on the towfish acoustic transducers) and pulse lengths. Lower frequency ranges are typically used where increased penetration is required, either because the targets of interest are deeper or the sediments are coarser and more difficult to penetrate with higher-frequency acoustic energy. Higher frequency pulses are typically used where increased resolution of shallow sediments is desired. Pulses that cover a broad range of frequencies can offer advantages of both. Long pulse lengths (20 ms or more) are typically preferred because they input greater acoustic energy into the water column and offer the widest range of frequencies. However, we have come across situations where a shorter pulse length is preferred, particularly in very shallow water (say, <10 m [33 ft]). In such situations, a long outgoing pulse can interfere with the seafloor return, sometimes quite severely; this situation is demonstrated in Figure 5. Anecdotally, we have noted that longer cable lengths (as, for example, when using a winch cable to power the towfish and transmit data) appear to increase the amplitude of the outgoing pulse and its potential for interference with the seabed reflections. We speculate that the longer cable creates a sufficient distortion in the outgoing and return signals such that the match filter is no longer a good "match." However, we do not have sufficient expertise to comment further on this issue. Additional study would be required to confirm the cause of these problems and could lead to environmental optimization of towfish configurations.

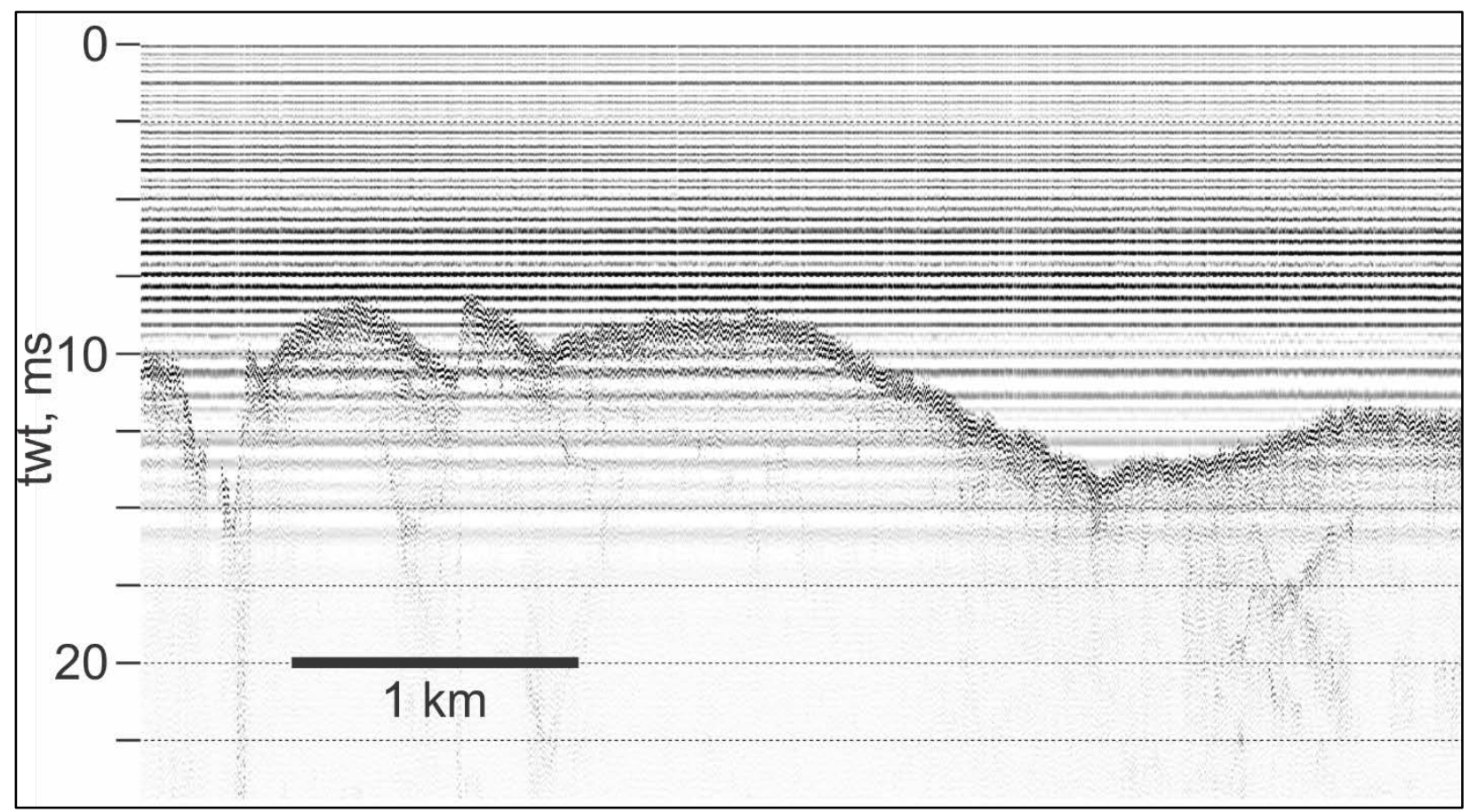

Figure 5. Outgoing Pulse Interference. (Example of an outgoing pulse interference [horizontal striping] with shallow seafloor returns that are less than a pulse length [in two-way time] below the towfish. This example is a sandy bottom, but such interference is independent of bottom type. Data were collected offshore of Panama City, Florida, using a SB-0512i towfish with a 20-ms 0.7-12 kHz pulse.) 
Choice of pulse configuration should be determined at the outset of a survey, prior to data collection; time should be reserved after deployment to experiment with the different pulses that are available for the towfish being used. It is preferable that the same pulse is used throughout the survey (even if shorter) so that all data have similar response (seismic reflectors and facies) to similar acoustic impedances in the subsurface geology. It is important that pulse configuration be documented throughout the survey.

\subsection{Tow Depth/Altitude and Water Multiples}

The most important consideration in choosing a tow depth (depth below sea surface) is to place the towfish deep enough that surface disturbances do not impact the data or are, at least, minimized; these primarily include the ship's prop wash and wave-generated bubbles (some chirp systems are float-towed but we do not have experience with this configuration to provide guidance).

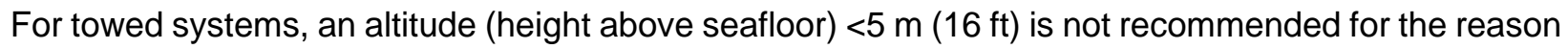
noted in Chapter 2.2, although working in shallow waters may preclude that consideration. In deep waters, operators will have the option of towing at greater depth (Edgtech towfish are rated to $300 \mathrm{~m}$ [984 ft]) to improve resolution. Towing at greater depth adds three important complexities to chirp surveys: (1) survey speed must be reduced to maintain greater tow depth; (2) the towfish is potentially subject to significant changes in tow depth resulting from minor changes in the ship's speed through the water (i.e., due to sea state, currents, etc.); and consequently (3) producing difficulty in estimating the layback correction for navigation. The latter two issues can lead to significant data artifacts and/or mismatches between crossing lines. Towing at shallow depth in deeper waters is also an option; we have collected high-quality data to as much as 600-m (1,969-ft) tow altitude. However, spherical spreading will degrade lateral resolution in this configuration.

Whether towing shallow or deep, it is important to have an independent means of determining tow depth as a function of time/ping number. Ideally, the chirp towfish itself includes a pressure transducer integrated into the system such that depth is written directly to the record header. However, this method represents a significant added cost to towfish purchase and is often not done. A second option is to mount an autonomous pressure transducer, which records depth as a function of time. These instruments are relatively inexpensive and easy to operate but added effort is required to synchronize those records with the chirp data records (Chapter 3.2.2). A third option is to interpret the water-bottom multiple (see below) and use that to estimate towfish depth (two-way time of the water-bottom multiple less twice the two-way time of the seafloor arrival). This option can be quite robust if the water multiple is strong, but it also requires preserving a long-enough data record to include the multiple, as well as additional processing effort. A fourth, but in practice less-accurate option, is to estimate fish depth by wire out, wire angle, and trigonometry and some effort to account for catenation of the wire. Yet a fifth, and highly accurate method, is to use an ultra-short baseline system (USBL; Chapter 2.4).

The presence of water multiples (Figure 6) is not a strong consideration for choosing a tow depth. The strongest multiple tends to be the water-bottom multiple, where the upward reflected signal reflects off the sea surface, again off the seabed, and then is recorded at the instrument. The depth 
of the water-bottom multiple (Figure 6) below the first seafloor arrival is independent of tow depth; i.e., the difference between the water-bottom multiple and seafloor two-way time is equal to the two-way time of the water column, not the two-way time below the towfish. The sea surface reflection (Figure 6), where the signal is recorded by the instrument after it is reflected from the sea surface, is occasionally observed, but it is typically not a strong arrival because the chirp transducer array is focused on upward-directed returns from the seafloor and below. We have also observed a multiple that may be unique to the EdgeTech chirp: a "towfish" multiple (Figure 6), where the reflected signal bounces off the flat bottom of the towfish, and again off the seafloor, before it is recorded again by the instrument, at which point it is exactly twice the altitude of the towfish in two-way time. This multiple is more likely to be observed with more reflective bottoms (e.g., sand) and low tow altitudes off the seabed.

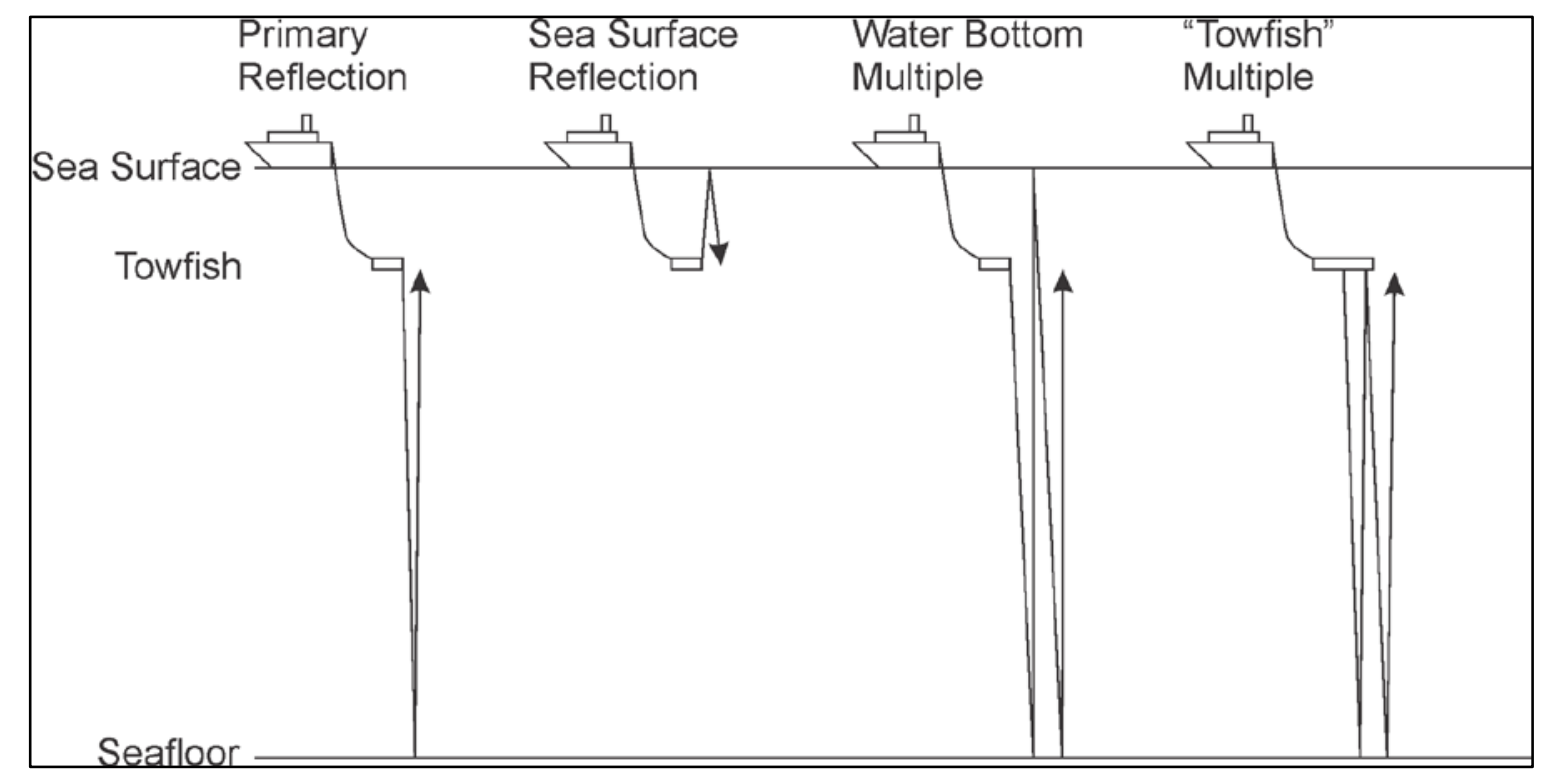

Figure 6. Multiples. (Schematic illustration of water multiples commonly observed in chirp surveying.)

\subsection{LAYBACK COMPUTATION}

The simplest means of computing a layback correction is to make a trigonometric estimation based on the known or assumed tow depth and the tow height and angle, combined with on-board measurements of the $X$ and $Y$ distance from the GPS antenna to the tow point. This computation has to be considered very approximate, however, with error greatly increasing with greater tow depth/line out. A far more accurate method is to use a USBL positioning systems, which can determine $\mathrm{X}, \mathrm{Y}$, and $Z$ position of the towfish relative to the ship's navigation. These systems operate using an acoustic array deployed over the side during survey that pings a signal to, and receives a signal from, the towfish. This relative position can often be integrated directly into the top-side electronics so that the navigational (and depth) corrections are made automatically. The major drawbacks are cost as well as technological and logistic complexity. 


\subsection{SURVEY DESIGN}

Prior to survey, a consistent survey identification should be determined and annotated to tracklines, and a consistent and logical line naming protocol adopted. Survey design will primarily be controlled by several factors unique to each survey: (1) the target stratigraphy; (2) the area of interest; (3) geographic constraints such as coastlines and bathymetry; (4) the resources available for survey; and (5) other survey assets being deployed. There are, however, several important principals of survey design that can be applied to any survey:

\section{Recon Before Attack}

Near-surface stratigraphy is often very complex, with heterogeneity at multiple scales. Depending on the survey goals, dense survey lines may be needed in some areas but not in others. A common example in a coastal setting would be a paleo-river channel filled by estuarine sediments. We often find, therefore, that a survey is best designed in two phases: first a reconnaissance survey to help constrain the location of the primary features of interest and then a dense survey to map those features in detail.

\section{Grids are Good}

A proper track design for seismic reflection should always endeavor to survey on a grid: parallel lines will minimize gaps in coverage and crossing lines will enable an interpreted horizon on one line to be confidently traced to the same horizon on all the other lines. In particular, an interpreter should be able to "loop" a horizon around the crossing lines of a survey grid such that the end point matches the starting point. Lines should be as straight as possible and not include turns in the data records (i.e., lines should be ended before the turn and started after completion of the turn).

\section{Orientation}

Some thought should be given to azimuthal orientation of grid surveys with respect to seafloor and subsurface depositional dips, meanders of non-linear features, and transit times between survey lines. Aligning grids over dipping structures as closely as possible to parallel/perpendicular to strike is preferred for interpretation.

\section{Supplementary Information}

During a survey, it is important to maintain accurate logs of events and conditions (Table 1). First and foremost, times and ping numbers of line start and end need to be logged. Environmental conditions such as sea state, tides, and currents, as well as configuration schematic, equipment log, crew, vessel, etc., must be noted if known and logged to validate issues encountered in post-processing and interpretation. These metadata are useful in perpetuity and will often be revisited by researchers not familiar with the individual survey; therefore, notes on external influences to data are necessary. 
Table 1. Example Survey Log.

\begin{tabular}{|c|c|c|c|c|c|c|}
\hline \multicolumn{7}{|c|}{ Underway CHIRP Log } \\
\hline Jday & \begin{tabular}{|l|l|} 
GMT \\
\end{tabular} & Local day & Local time & Line name & Pi g Number| & Watchstander Notes \\
\hline 145 & $17: 29$ & 25-May & $12: 29$ & Galv2017_Line12 & 43851 & Start of Galv2017_Line12 \\
\hline 145 & $17: 47$ & 25-May & $12: 47$ & Galv2017_Line12 & 49996 & Channel-like feature \\
\hline 145 & $17: 55$ & 25-May & $12: 55$ & Galv2017_Line12 & & Beginning Turn going $\sim 5-6$ knots \\
\hline 145 & $17: 55$ & 25-May & $12: 55$ & Galv2017_Line12 & 52440 & End of Galv2017_Line12 \\
\hline 145 & $17: 56$ & 25-May & $12: 56$ & Galv2017_Line13 & 53220 & Start of Galv2017_Line13 \\
\hline 145 & 18:15 & 25-May & $13: 15$ & Galv2017_Line13 & 58511 & Facies change; mound like feature \\
\hline 145 & $18: 21$ & 25-May & 13:21 & Galv2017_Line13 & 59943 & Deeper incision inside the valley, change in facies \\
\hline 145 & $18: 40$ & 25-May & $13: 40$ & Galv2017_Line13 & & Poor data quality due to severe heave \\
\hline 145 & $18: 45$ & 25-May & $13: 45$ & Galv2017_Line13 & & Lowering fish down $2 \mathrm{~m}$ more \\
\hline 145 & $18: 53$ & 25-May & $13: 53$ & Galv2017_Line13 & 69780 & End of Galv2017_Line13 \\
\hline 145 & $18: 53$ & 25-May & $13: 53$ & Galv2017_Line14 & 69838 & Start of Galv2017_Line14 \\
\hline 145 & 19:01 & 25-May & 14:01 & Galv2017_Line14 & 72076 & Stop recording due to poor data quality \\
\hline 145 & 19:03 & 25-May & $14: 03$ & & & Restarted CHIRP computer and self system check \\
\hline 145 & 19:12 & 25-May & $14: 12$ & & & New heading, CHIRP onboard \\
\hline 145 & $19: 16$ & 25-May & $14: 16$ & & & Testing fish onboard \\
\hline 145 & 19:19:00 & 25-May & $14: 19$ & & & Testing CHIRP again onboard \\
\hline 145 & 19:19:00 & 25-May & $14: 19$ & & & Fish sidecable connection problem. End of CHIRP survey \\
\hline
\end{tabular}

\section{PROCESSING}

We have found that even a quick and automated level of processing of chirp data can render the envelope data much more interpretable, and the underutilized, higher-resolution, full-waveform data more accessible. We have developed a proposed chirp processing flow to perform these tasks. At its core this processing flow is an iterative high-resolution seafloor picking and smoothing scheme designed to be as robust, accurate, and automated as possible. Selected digital signal processing is also performed on the full-waveform data.

EdgeTech chirp data are typically recorded as ".jsf"-formatted files, a native EdgeTech format that includes four different data channels - "real," "imaginary," "envelope," and "spectrum." The two channels of interest to the following processing scheme are "real," which is the full-waveform record, and "envelope," which is the envelope-processed data more commonly seen (Figures 2, 3, and 7). Following data archiving (primary recording to top-side main drive and backup to secondary external drive), and prior to processing, these records must be converted to SEG-Y format files, which can be done with a number of available utilities. If a single survey line consists of multiple individual files, we find it useful to first convert and then concatenate these records into a single SEG-Y file for processing. The EdgeTech acquisition software also provides an option to record directly to SEG-Y format. However, this format only includes envelope records; full waveform is only retained in the .jsf files. As noted above, we highly recommend acquiring field data in .jsf or an analogous format, such as .keb files for Knudsen systems, that retains both data types. 


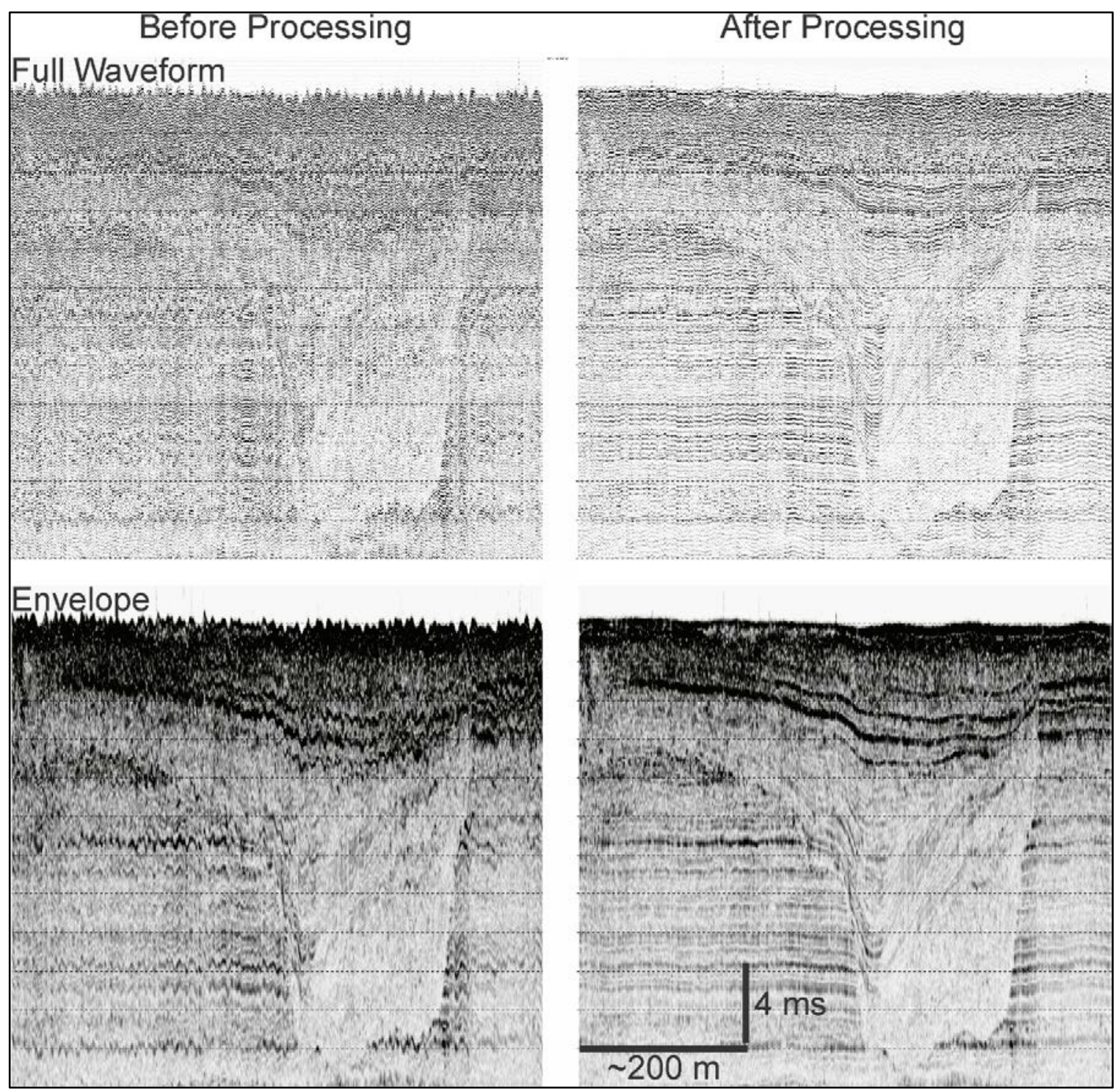

Figure 7. Examples of Before-and-After Processing of Full-waveform and Envelope Chirp Records. (Images exhibit highly detailed stratigraphic structure and demonstrate the level of improvement in stratigraphic imaging that can be attained with chirp processing. Data were collected offshore of Freeport, Texas, using an EdgeTech 512i towfish with a 20-ms 0.7-12 kHz pulse.)

Our chirp processing scheme involves three primary data streams. The first of these streams includes the critical step of picking the seafloor (to within a fraction of a wavelength at $\sim 5,000 \mathrm{~Hz}$, or about $0.1 \mathrm{~ms}$ ), which provides the basis for the other two data streams: real and envelope processing. Processing of real and envelope data in turn involves three steps: static corrections (heave compensation, towfish depth, and tides); signal processing to improve image clarity; and layback correction for navigation. 


\subsection{BOTTOM PICKING}

The key step to being able to remove heave artifacts from chirp data, as well as for some signal processing, is to generate a precise pick of the seafloor reflection. A fully-automated bottom picker is desirable for ease-of-use but, in our experience, can fail regularly in the presence of high noise, low seafloor signal, or amplitude variability. Our own bottom-picking algorithm involves an iterative process, beginning with a coarse pick using a simple threshold algorithm, and successively refining using both automated methods (Figure $8 \mathrm{~A}$ ) and, optionally, user interaction in more difficult cases. The details of this algorithm are complex and beyond the scope of this document. Once completed, the bottom pick enables the user's ability to move individual records up or down (i.e., apply a "static") in relation to the seafloor arrival. Heave filtering, described below, is one such application. It is also possible to flatten record to the seafloor by applying a static equal to the inverse of the seafloor depth (Figure 8B), which is useful for quality control, i.e., enhance both the user's ability to visually identify bad bottom picks and the algorithm's ability to iteratively refine the picks. Flattening is also a prerequisite for some of the processing steps described below. The seafloor flattening step is reversed (by subtracting the flattening static) later in the processing stream to preserve true topographic features at the seafloor.

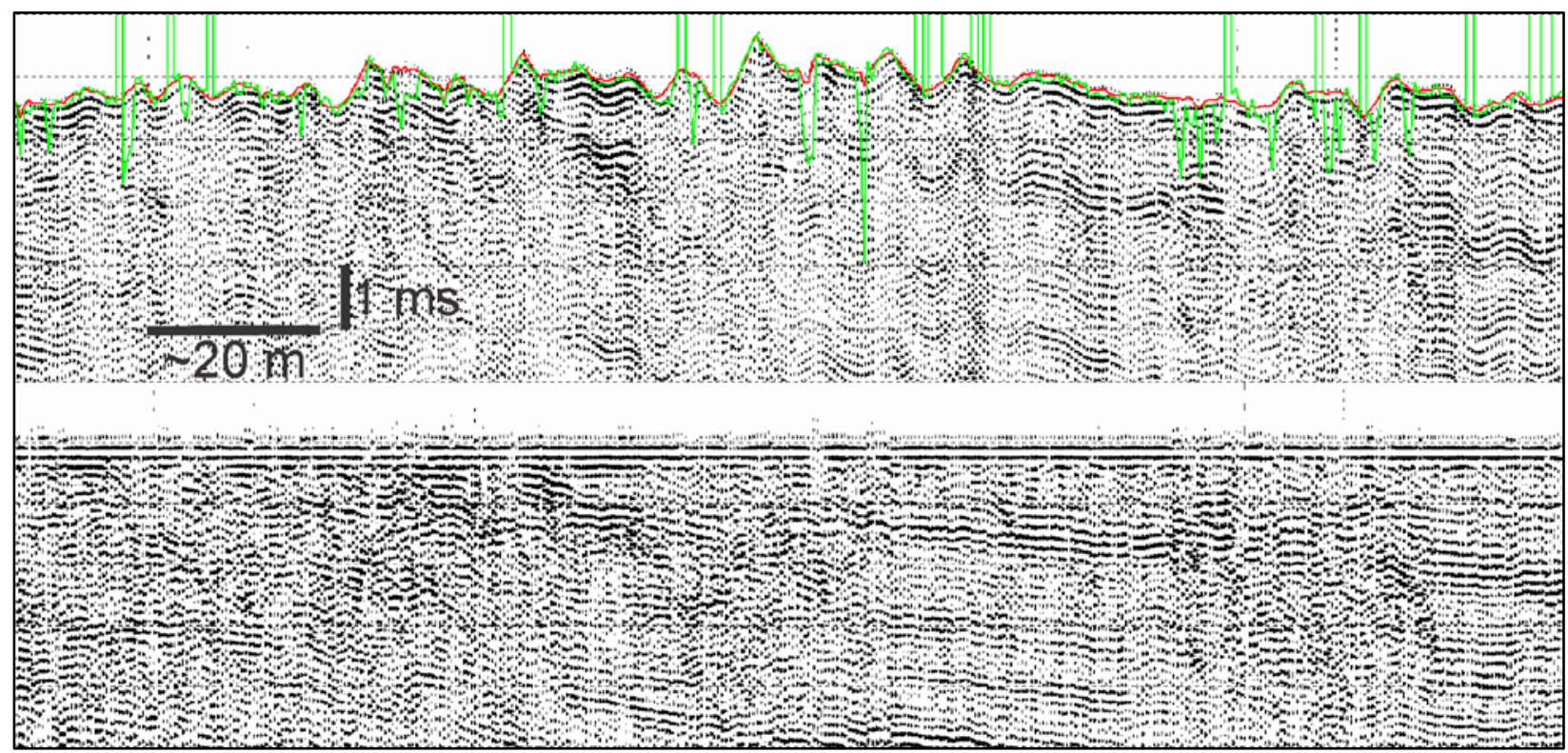

Figure 8. Bottom Picking. (A) Highly enlarged section of a chirp full-waveform record showing an initial bottom pick (green), which has many spurious picks, and an iteratively refined bottom pick (red). (B) Same record shown in (A) flattened to the seafloor defined by the refined bottom pick. These data are a subsection of data shown in Figure 2.

\subsection{STATIC CORRECTIONS}

\subsubsection{Recording Delay Correction}

The data are corrected for any recording delay (nonzero start recording time, also called deepwater delay) that may have been used in the field by applying the appropriate static correction. This is often the case when operating in deep water; a delayed start of the recording time (a simple 
option in EdgeTech systems, for example) can be used skip over large quantities of potentially useless water column returns and thereby keep record lengths and file sizes to manageable values.

\subsubsection{Towfish Depth}

A time series for towfish depth is recorded in the field and is used to correct to a sea-surface datum. As noted in Chapter 2.3, this depth can be estimated using a variety of methods, including cable length/angle, a pressure sensor mounted on or integrated into the towfish, or ascertained with a USBL system. For best results, this step should be performed before the seafloor picking.

\subsubsection{Heave Compensation}

Heave artifacts are present when the towfish is pulled up and down as the ship responds to wave motion. They are at once the most destructive factors in image quality (e.g., Figures 2 and 7) yet the easiest to mitigate once the seafloor arrival has been picked. To correct for heave, the seafloor picks are smoothed using a user-defined (nominally 35-75 pings) low-pass filter, applied to the bottom arrival trace, that is large enough to average out heave artifacts. The difference between the filtered and unfiltered seafloor picks forms a static correction to correspondingly shift the traces up or down to compensate for heave (Figure 9A, 9B). Care must be taken during this step, if possible, to not over-smooth the seafloor and remove true topography (although this is not always possible if seafloor features are of similar wavelength to heave artifacts). Heave correction values as calculated on the full-waveform data are stored in a database and applied identically to both envelope and full-waveform data. An important best practice for processed data is to incorporate values for final picked seafloor time, smoothed seafloor time, and seafloor static into the trace header. This enables heave compensation filtering to be "undone" so that other correction algorithms can be applied (e.g., fitting the picked seafloor to a known bathymetric surface).

\subsubsection{Tide Corrections}

A tide time series, either observed or predicted, is used to correct to Mean Low Tide or any other local datum. This time series should be smoothed as necessary beforehand to avoid artifact. Tide corrections are needed to ensure that reflectors on crossing lines will have the same two-way time.

\subsection{SIGNAL PROCESSING}

Signal processing (i.e., frequency filtering, deconvolution, gain correction, and water column muting) is performed after the data have been temporarily flattened at the seafloor (Figure 8B) for best results. Some signal processing methods, such as frequency filtering and deconvolution, can only be applied to the full-waveform data traces. 


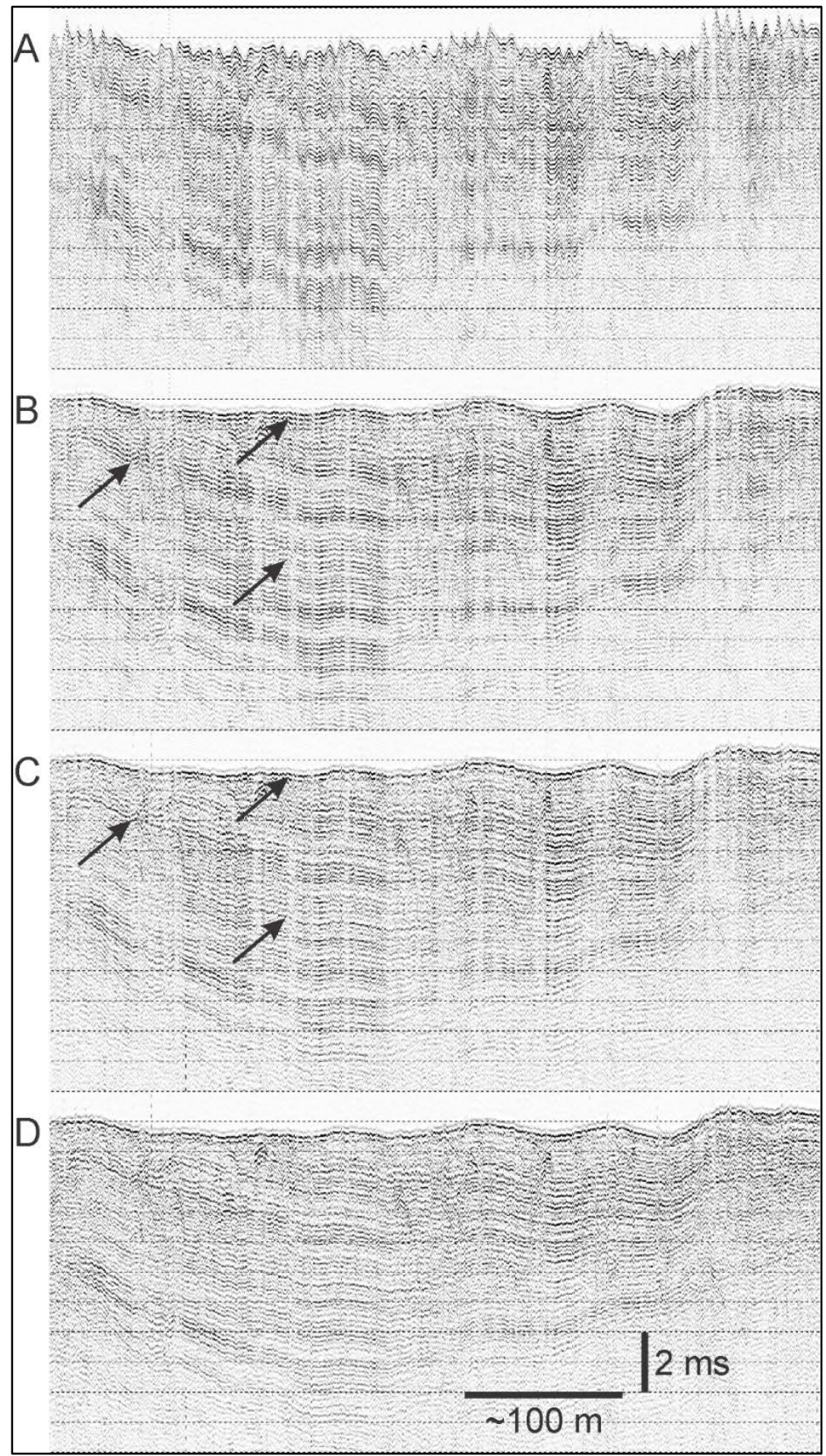

Figure 9. Key Chirp Processing Steps. (A) Raw full-waveform record collected on the Rio Grande delta (also shown at different scale in Figure 2). (B) After bottom picking and heave filtering. (C) After secondary deconvolution. Arrows in $(B)$ and $(C)$ identify several examples of ringy reflectors (including seafloor) that have been sharpened by the secondary deconvolution. (D) After gain correction, which reduces vertical banding. 


\subsubsection{Frequency Filtering}

Full-waveform data are bandpass-filtered using a filter comparable to the source wavelet band (e.g., 700- to 12,000-Hz Butterworth Filter, with a filter length of 91 samples). This step primarily removes low-frequency towing noise.

\subsubsection{Deconvolution}

Ideally, if the data are matched-filtered by the outgoing pulse, chirp data should not require additional signal processing. However, the match filter is not perfect, presumably owing to differences between modeled and actual outgoing pulse waveforms; this results in ringy reflections in the full-waveform record (Figure 9B). Image quality can therefore be significantly improved with a standard predictive deconvolution technique. To do so, we first empirically estimate a "source" signal by stacking multiple seafloor reflections; this is, of course, not the actual chirp source, but rather a residual signal that remains after initial, imperfect, match filtering. Full-waveform data are then deconvolved using this empirical function. In practice for our data, we use a deconvolution operator calculated from the chirp data (e.g., a 31-trace predictive deconvolution with a filter length of 15 samples and a prediction distance of 4 samples). Applying this procedure to temporarily seafloor-flattened data (Figure 8A) simplifies this procedure by enabling use a constant design window (here $10 \mathrm{~ms}$ ) rather than one that moves up and down with the seafloor. Additional details regarding predictive deconvolution of chirp data can be found in Baradello (2014). After the deconvolution is performed, the seafloor-flattening is reversed (Chapter 3.1) to return the seafloor arrival to the appropriate depth; the net visual result is to give the data a less ringy quality, with more sharply defined reflectors (Figure 9C).

\subsubsection{Gain Correction}

Amplitudes are corrected to account for lateral variation spatially (due largely to towfish pitch) and temporally to account for transmission loss and spherical divergence. This step is done using a water-velocity spherical divergence correction followed by a windowed lateral trace balance. This gain preserves the true amplitudes of the data, and your final data product can be saved with this type of gain correction applied. An additional automatic gain control (30 ms length is common) scaling is optional and produces improved displays (Figure 9D), but this gain will mask true amplitude variations. Therefore, an automatic gain control is advised for display purposes only and not for data processing and archiving.

\subsubsection{Water Column Muting}

Data may be muted above the picked seafloor arrival time to remove any water column noise. This is done primarily for generating a cleaner display for publication. This step should not be performed, however, if there are features of interest in the water column (e.g., active gas seeps). 


\subsection{LAYBACK CORRECTIONS}

The $X$ and $Y$ layback corrections, either estimated from tow observations, or determined acoustically with USBL location instruments, are applied to the original GPS navigation recorded (either in real time, if the acquisition software is so enabled, or in post processing otherwise) in the SEG-Y trace headers. These new values are then inserted into the trace headers, replacing the original positions. Original SEG-Y files are retained to preserve original navigation recordings, but the layback corrected files are used for stratigraphic interpretation.

Chirp data are generally recorded with GPS data in the trace headers and, thus, are in geographic coordinates (latitude and longitude). However, for use in interpretation software, it can be useful (or for some software required) to convert geographic position output (commonly listed as arc-seconds in the trace header where longitude is the $X$ value and latitude the $Y$ value) to Universal Transverse Mercator (or other projections) where the $X$ and $Y$ values are generally meters or feet. This conversion assists in distance, area, and volume calculations done during interpretation. No map projection can simultaneously preserve area, distance, shape, and angle so selecting a project for the final data use is advised.

\section{DATA ARCHIVING REQUIREMENTS}

\subsection{Database ARChIVING}

Chirp data will be archived at a number of locations, such as the National Science Foundation-supported Academic Seismic Portal (ASP), National Centers for Environmental Information (NCEI), and within BOEM's Marine Minerals Information System for discovery.

ASP Requirements: At a minimum, the ASP require chirp data in SEG-Y format with navigation either in the headers or as a stand-alone file tied to either ping numbers or time. The ASP generates images for each file, places navigation in the headers (if necessary), and extracts any processing history information from the SEG-Y headers. The ASP archives the SEG-Y data, ASCII navigation files, processing history files, images, and any related documents, making them available on the ASP.

BOEM Requirements: BOEM requires following the National Oceanic and Atmospheric Administration's archiving guidelines (https://www.ncei.noaa.gov/archive). The NCEI and BOEM archive the SEG-Y data, .jsf files, ASCII navigation files, processing history files, images, metadata, and any related documents, making them available on NCEI and discoverable through the Marine Minerals Information System. Additionally, BOEM will maintain all project data deliverables. A footprint will be added to BOEM's Marine Minerals Information System (database), which will link to products (grids, tiff images, or mosaics). 


\subsection{Best PRactices for ARChiving}

Archive the following:

(1) raw acquisition system file format containing all data channels (.jsf format for EdgeTech systems);

(2) SEG-Y files of both processed envelope and full-waveform data with navigation in the headers as arc seconds in bytes 73-76 and 77-80;

(3) cruise report;

(4) cruise logs;

(5) lineage (all step in regards to how data has been collected, processed, or manipulated); and

(6) metadata records ISO/FGDC (International Standards Organization/Federal Geographic Data Committee) standards (https://www.fgdc.gov/metadata/geospatial-metadata-standards).

\section{REFERENCES}

Baradello, L. 2014. An improved processing sequence for uncorrelated Chirp sonar data. Marine Geophysical Research 35:337-344.

EdgeTech. N.D. 3200 sub-bottom profiling system. 2 pp. Internet website: https://www.edgetech.com/wp-content/uploads/2017/04/3200-Brochure-04-26-17.pdf.

Goff, J.A., J.D. Chaytor, A.H. Reed, S. Liu, P.S. Wilson, and D.P. Knobles 2016. The coarse- to fine-grained boundary beneath the New England Mud Patch: Evidence from seismic and core data for an abrupt post-transgressive change in hydrologic regime on the continental shelf. AGU Fall Meeting, Abstract EP24B-01.

Gulick S.P.S., A.E. Shevenell, A. Montelli, R. Fernandez, C. Smith, S. Warny, S.M. Bohaty, C. Sjunneskog, A. Leventer, B. Frederick, and D.D. Blankenship. 2017. Initiation and long-term instability of the East Antarctic ice sheet. Nature 552:225-229.

Klauder, J.R., A.C. Price, S. Darlington, and W.J. Albersheim. 1960. The theory and design of chirp radars. The Bell System Technological Journal 39:745-808.

Schock, S.G., L.R. LeBlanc, and L.A. Mayer. 1989. Chirp subbottom profiler for quantitative sediment analysis. Geophysics 54:445-450.

Twichell, D.C., C.E. McClennen, and B. Butman. 1981. Morphology and processes associated with the accumulation of the fine-grained deposit on the southern New England shelf. Journal of Sedimentary Petrology 51:269-280. 



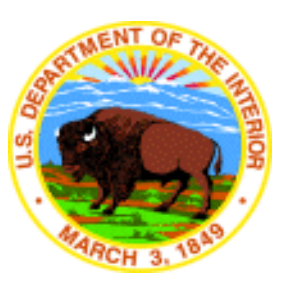

\section{The Department of the Interior Mission}

The Department of the Interior protects and manages the Nation's natural resources and cultural heritage; provides scientific and other information about those resources; and honors the Nation's trust responsibilities or special commitments to American Indians, Alaska Natives, and affiliated island communities.

\section{The Bureau of Ocean Energy Management Mission}

The Bureau of Ocean Energy Management (BOEM) is responsible for managing development of U.S. Outer Continental Shelf energy and mineral resources in an environmentally and economically responsible way. 